OPEN ACCESS

Edited by:

Juarez Antonio Simões Quaresma, Federal University of Pará, Brazil

Reviewed by: Euan Robert Brown, Heriot-Watt University, United Kingdom Ruchi Tiwari,

Veterinary University (DUVASU), India

*Correspondence:

Vishvanath Tiwari

vishvanath7@yahoo.co.in

tThese authors have contributed equally to this work.

Specialty section: This article was submitted to Microbial Immunology, a section of the journal

Frontiers in Immunology

Received: 20 May 2017 Accepted: 31 July 2017 Published: 16 August 2017

Citation:

Tiwari V, Tiwari M and Solanki V (2017) Polyviny/pyrrolidone-Capped Silver Nanoparticle Inhibits Infection of Carbapenem-Resistant Strain of

Acinetobacter baumannii in the Human Pulmonary Epithelial Cell.

Front. Immunol. 8:973. doi: 10.3389/fimmu.2017.00973

\section{Polyvinylpyrrolidone-Capped Silver Nanoparticle Inhibits Infection of Carbapenem-Resistant Strain of Acinetobacter baumannii in the Human Pulmonary Epithelial Cell}

\author{
Vishvanath Tiwari ${ }^{\star+}$, Monalisa Tiwari ${ }^{\dagger}$ and Vandana Solanki \\ Department of Biochemistry, Central University of Rajasthan, Ajmer, India
}

Acinetobacter baumannii, an opportunistic ESKAPE pathogen, causes respiratory and urinary tract infections. Its prevalence increases gradually in the clinical setup. Pathogenicity of Acinetobacter is significantly influenced by its ability to infect and survive in human pulmonary cells. Therefore, it is important to study the infection of A. baumannii in human pulmonary host cell (A-549), monitoring surface interacting and internalized bacteria. It was found that during infection of $A$. baumannii, about $40 \%$ bacteria adhered to A-549, whereas $20 \%$ got internalized inside pulmonary cell and induces threefold increase in the reactive oxygen species production. We have synthesized polyvinylpyrrolidone (PVP)-capped AgNPs using chemical methods and tested its efficacy against carbapenem-resistant strain of $A$. baumannii. PVP-capped silver nanoparticles (PVP-AgNPs) (30 $\mu \mathrm{M})$ have shown antibacterial activity against carbapenem-resistant strain of $A$. baumannii and this concentration does not have any cytotoxic effect on the human pulmonary cell line $\left(\mathrm{IC}_{50}\right.$ is $\left.130 \mu \mathrm{M}\right)$. Similarly, PVP-AgNPs treatment decreases $80 \%$ viability of intracellular bacteria, decreases adherence of $A$. baumannii to A-549 (40 to $2.2 \%$ ), and decreases intracellular concentration (20 to 1.3\%) of $A$. baumannii. This concludes that PVP-AgNPs can be developed as a substitute for carbapenem to control the infection caused by carbapenem-resistant $A$. baumannii.

\section{Keywords: Acinetobacter baumannii, polyvinylpyrrolidone-capped silver nanomaterial, host-pathogen interaction, carbapenem resistance, silver nanomaterial}

\section{INTRODUCTION}

Acinetobacter baumannii, an ESKAPE pathogen, causes pneumonia, urinary tract infections, and respiratory infections, and its prevalence in clinical setup increases with time $(1,2)$. ESKAPE pathogen causes hospital-acquired infection and includes Enterococcus faecalis, Staphylococcus aureus, Klebsiella pneumoniae, A. baumannii, Pseudomonas aeruginosa, and Enterobacter species. The lethality of $A$. baumannii is due to the development of resistance against most of the antibiotics used to treat it. Resistance against carbapenem (2-6), the most effective $\beta$-lactams antibiotic, used against Acinetobacter, is one of the major concerns. Inflammation in lung is one of the important symptoms of pneumonia caused by A. baumannii resulting in epithelial barrier destruction (7). Interaction between A. baumannii and human pulmonary cells (alveolar epithelial) leads to infection because of its adherence and invasion into these cells (8-10) and induces cellular death (8). Pathogenicity of 
Acinetobacter is significantly influenced by its ability to survive in the human pulmonary cells. Therefore, it is important to study the interaction of A. baumannii with human pulmonary host cell.

AgNPs (silver nanoparticles) have antimicrobial property against diverse microbes, probably due to their different mechanisms of antimicrobial action $(11,12)$. Polyvinylpyrrolidone (PVP) is a neutral stabilizer and less sensitive to surface charge screening processes like $\mathrm{pH}$ change and ionic strength (13). Recent reports have shown that PVP-capped AgNPs are more stable than other AgNPs $(14,15)$. PVP-capped AgNPs are also less toxic to the mammalian cells (16). Likewise, interaction of PVP-capped silver nanoparticles (PVP-AgNPs) with serum proteins affects its in vivo antimicrobial activity. It has been reported that PVP-capped AgNPs have better in vivo antimicrobial activity than other capped AgNPs (17). Hence, they can be used as a substitute to the carbapenem. Therefore, in the present study, we have monitored the infection of carbapenem-resistant strain of $A$. baumannii to the human pulmonary (alveolar epithelial) cell line A-549. Further, we have also monitored the surface interacting and internalized bacteria and tested the efficacy of PVP-capped AgNPs on the infection of A. baumannii in A-549 cell line. The present result might help to understand the infection caused by A. baumannii to human pulmonary cell as well as control of infection caused by it using the PVP-capped silver nanomaterial.

\section{MATERIALS AND METHODS}

\section{Bacterial Strain}

All the work related to cell line and bacteria were performed aseptically, under laminar airflow. Clinical strain RS-307 of A. baumannii was grown in Luria-Bertani broth (LB) media at $37^{\circ} \mathrm{C}$ till it reached optical density to $0.6 \mathrm{OD}$. After sufficient bacterial growth, streaking was done on the Luria agar plate to isolate the single bacterial colony. Single colony was used for suspension culture. Prior to coinfection, bacterial culture was centrifuged and re-suspended in PBS to remove deleterious effects of toxins (cytotoxins) present in the culture.

\section{Human Pulmonary Cell Line Culture}

The human alveolar basal epithelial cell line A-549 (purchased from Cell repository, NCCS, Pune) was cultured in high glucose Dulbecco's Modified Eagle Medium (DMEM) supplemented with $10 \%$ heat inactivated fetal bovine serum albumin (heat inactivation was performed at $56^{\circ} \mathrm{C}$ for $30 \mathrm{~min}$ ), amphotericin $\mathrm{B}$ $(2.5 \mu \mathrm{g} / \mathrm{ml})$, vancomycin $(50 \mu \mathrm{g} / \mathrm{ml})$, gentamicin $(50 \mu \mathrm{g} / \mathrm{ml})$, and $1 \%$ HEPES in a humidified, $5 \% \mathrm{CO}_{2}$ at $37^{\circ} \mathrm{C}$. Passage of A-549 human pulmonary cell line in $25 \mathrm{~cm}^{2}$ flask was done after every 2-3 days intervals when they were confluent. The cells were seeded for $24 \mathrm{~h}$ in 96 well plates for MTT and LDH assay and 6-well plates for coinfection with the A. baumannii.

\section{Preparation of Cell Line and Bacterial Culture for Infection}

Confluent A-549 cells flask was washed twice with PBS buffer (pre-warm at $37^{\circ} \mathrm{C}$ ). The cells were detached with the help of
$0.05 \%$ trypsin-EDTA and complete media was added. The suspension was centrifuged and cells pellet were re-suspended in the fresh DMEM medium containing 10\% fetal bovine serum without antibiotics, at a concentration of $2 \times 10^{5}$ cells $/ \mathrm{ml}$. Simultaneously, bacterial culture was inoculated in $100 \mathrm{ml}$ of LB broth and was grown at $37^{\circ} \mathrm{C}$ with vigorous shaking $(180 \mathrm{rpm})$ till optical density reached to 0.6 . We have counted colony-forming unit (CFU) of the bacteria before coinfection.

\section{Infection of A-549 Cells by RS-307 Strain of $A$. baumannii}

A-549 cells were grown at $37^{\circ} \mathrm{C}$ in $5 \% \mathrm{CO}_{2}$ till they reached at least $90 \%$ confluency without contamination. The cells were washed with pre-warm PBS. $1 \mathrm{ml}$ of fresh medium supplemented with $10 \%$ serum without antibiotics was added to each well. The control wells were prepared by adding fresh medium without A-549 cells in three wells. These wells were used as a blank for addition of bacterial strains. Coinfection was achieved by adding an aliquot of each bacterial culture to each well containing A-549 cells (in triplicate) and in the blank. This coinfection represents MOI (multiplicity of infection) of 3:1 (bacteria, $1.2 \times 10^{7}$ : cells, $0.4 \times 10^{7}$ ). Infected A-549 cells were incubated in incubator for $24 \mathrm{~h}$ at $37^{\circ} \mathrm{C}$ with $5 \% \mathrm{CO}_{2}$.

\section{CFU Counting of Different Stages of the Infections}

We have counted bacterial populations of four different stages of infection, i.e., before coinfection, remain non-interact during coinfection (suspension culture in DMEM media which contain the free bacteria), interacting or adhered bacteria on the surface of A-549 (which were isolated after mixing of cell pellet in the PBS and centrifugation, as explained in next section) and internalized bacteria into A-549 (which were isolated after homogenization). The CFU was determined for above four stages.

\section{Protein Extraction}

After $24 \mathrm{~h}$ incubation, washing was done 3 times with pre-warm PBS. $1 \mathrm{ml}$ of PBS (containing $0.1 \mathrm{mM}$ protease inhibitor PMSF) was added. Adhered bacteria were detached and centrifuged at $3000 \mathrm{~g}$ for $5 \mathrm{~min}$ to separate the loosely adhered bacteria. The pellet was dissolved in $1 \mathrm{ml}$ PBS (with $0.1 \mathrm{mM}$ PMSF). The dissolved pellet was homogenized for $1 \mathrm{~min}$. Homogenized sample were centrifuged at $7000 \mathrm{~g}$ for $10 \mathrm{~min}$. The supernatant was stored at $-80^{\circ} \mathrm{C}$ containing A-549 cell lines proteins. The pellet (containing internalized bacteria) was suspended in $1 \mathrm{ml}$ PBS with $0.1 \mathrm{mM}$ PMSF. This suspended pellet was sonicated for three cycles of $30 \mathrm{~s}(20 \mathrm{kHz}, 130 \mathrm{~W})$ with the interval of $1 \mathrm{~min}$. The sonicated samples were centrifuged at $10000 \mathrm{~g}$ for $10 \mathrm{~min}$. The supernatant contained bacterial protein and was stored at $-80^{\circ} \mathrm{C}$. The samples were collected before homogenization and sonication, and used for bacterial CFU counting that represent adhered and internalized bacteria, respectively. Protein concentrations were measured for bacterial samples (internalized and adhere) and cell line (before and after bacterial infection) using Bradford methods. 


\section{Preparation of PVP-Capped AgNPs and In Vitro Antimicrobial Activity Test}

Polyvinylpyrrolidone-capped AgNPs were prepared as per our published methods (12). The size and zeta-potential of synthesized PVP-capped AgNPs were monitored using dynamic light scattering-based particle analyzer. In vitro susceptibility of PVPAgNPs $(30 \mu \mathrm{M})$ was performed on carbapenem-resistant strain of $A$. baumannii using disc diffusion assay and growth kinetics analysis as per our published protocol (18).

\section{Treatment of PVP-Capped AgNPs and CFU Counting for Different Stages of the Infections}

For the treatment, four T-25 flasks were prepared. First flask was used as a control for cell line, second flask was used for bacterial infection, third flask was for AgNPs treatment after bacterial infection, and fourth flask as negative control for AgNPs treatment. All four flasks were incubated at $37^{\circ} \mathrm{C}$ for $24 \mathrm{~h}$ with $5 \% \mathrm{CO}_{2}$. Coinfection was achieved by adding $1.2 \times 10^{7} \mathrm{CFU}$ that represents MOI of 3:1 (bacteria, $1.2 \times 10^{7}$ : cells, $0.4 \times 10^{7}$ ). Infected A-549 cells were incubated in the $\mathrm{CO}_{2}$ incubator at $37^{\circ} \mathrm{C}$ for $24 \mathrm{~h}$ with $5 \% \mathrm{CO}_{2} .500 \mu \mathrm{l}$ of culture media was taken for counting non-interacting bacteria. The media was discarded gently and flasks were washed mildly two times by $2 \mathrm{ml}$ PBS. All the washed cell lines were collected in $1 \mathrm{ml}$ PBS. This suspended cell line mixture contains surface interacting bacteria and cell line (with or without engulf bacteria). This mixture was centrifuged at $3000 \mathrm{~g}$ for $5 \mathrm{~min}$ and supernatant was used for CFU counting of interacting bacteria. The collected samples were homogenized for $3 \mathrm{~min}$ ( $1 \mathrm{~min}$ pulse each) and centrifuged at 7,000g for $10 \mathrm{~min}$. The supernatant contains cell line proteins and pellet contains engulfed bacteria. The pellet was dissolved in $500 \mu \mathrm{l}$ PBS and used for CFU counting of engulf bacteria. Suspended bacteria was further sonicated and centrifuged. The supernatant contained bacterial proteins. The cell line proteins and bacterial proteins of different conditions were used for the SDS-PAGE analysis.

\section{Cytotoxic Effect of PVP-Capped AgNPs on the A-549 Cell Line and Survival of}

\section{A. baumannii after PVP-AgNPs Treatment}

Cytotoxic effect of PVP-capped AgNPs (15-300 $\mu \mathrm{M})$ on the A-549 cell line was investigated using MTT (EZcount ${ }^{\mathrm{TM}}$ MTT Cell Assay Kit) and $\mathrm{LDH}$ assay (EZcount ${ }^{\mathrm{TM}}$ Lactate Dehydrogenase Cell Assay Kit) to find the non-toxic dose as well as $\mathrm{IC}_{50}$ concentration of PVP-AgNPs.

\section{Cytotoxic Effect of PVP-AgNPs on the Internalized $A$. baumannii}

Viability of A. baumannii in infected A-549 cell line was monitored using MTT assay. The triplicated experiment was performed on A-549 alone, A-549 cell line infected with A. baumannii, and A. baumannii-infected A-549 cell line treated with PVP-AgNPs. The viable internalized bacteria were calculated by subtracting total viability of infected A-549 cell line with A. baumannii by the viability of uninfected A-549 cell line.

\section{Reactive Oxygen Species (ROS) Formation during Infection and PVP-Capped AgNPs Treatment}

Reactive oxygen species production was monitored by nitroblue tetrazolium (NBT) reduction assay for uninfected A-549 cell lines, A. baumannii infected A-549 cell lines (A-549), and A. baumannii-infected cell lines after PVP-AgNPs treatment. NBT stock solution $(10 \mathrm{mg} / \mathrm{ml})$ was prepared in distilled water and kept in dark at $4^{\circ} \mathrm{C}$. A working NBT solution (0.3\%) was prepared in culture medium just before utilization. It was diluted three times in each well, giving a final concentration of $0.1 \%$ NBT in the well. $50 \mu$ l supernatants were eliminated when the cells were adhered and replaced it by $50 \mu \mathrm{l}$ of $0.3 \%$ NBT working solution. After $2 \mathrm{~h}$ of incubation, supernatant was removed and cells were fixed by adding of $200 \mu \mathrm{l}$ of methanol and washed twice with $70 \%$ methanol, then dried. The formazan deposits were solubilized in $120 \mu \mathrm{l} 2 \mathrm{M} \mathrm{KOH}$ and $140 \mu \mathrm{l} \mathrm{DMSO}$. After vigorous mixing of all the contents of wells, absorbance was recorded at $620 \mathrm{~nm}$ using UV-Vis spectrophotometer. To remove the contribution coming from the ROS produced by A. baumannii, a bacterial control was also taken.

\section{RESULTS}

The adherence and persistence ability of A. baumannii on the host cell is central to its pathogenicity. To cause host cell infections, bacteria first colonize on the surface of the host. They express different types of adhesin molecules for attachment to host cells. These adhesins bind the surface soluble proteins of the host and act as a bridge between host and bacteria. Adherence is the first most important step than invasion and secretion of toxins. Adhered bacteria invade into the host cell and causes infection. In this study, we have used RS-307 strain of A. baumannii, which is a multidrug resistant strain of $A$. baumannii and have high $\mathrm{MIC}(>64 \mu \mathrm{g} / \mathrm{ml})$ for imipenem (a carbapenem), and A-549 cell line, which is a human pulmonary (alveolar epithelial) cells. This cell line has been chosen as $A$. baumannii causes pneumonia that is associated with lungs.

TABLE 1 | Comparative display of colony-forming unit (CFU) counting at different stages of $A$. baumannii infection in absence and presnce of PVP-capped silver nanoparticles (PVP-AgNPs).

\begin{tabular}{|c|c|c|c|c|}
\hline Condition for the culture & Bacteria used for coinfection & $\begin{array}{c}\text { Non-interacting bacteria } \\
\text { CFU }\end{array}$ & $\begin{array}{l}\text { Surface interacting bacteria } \\
\text { CFU }\end{array}$ & $\begin{array}{l}\text { Engulf or interlized bacteria } \\
\text { CFU }\end{array}$ \\
\hline A-549+ bacteria & $1.2 \times 10^{7}(100 \%)$ & $0.50 \times 10^{7}(41.66 \%)$ & $47.6 \times 10^{5}(39.66 \%)$ & $22.1 \times 10^{5}(18.41 \%)$ \\
\hline A-549 + bacteria + PVP-AgNPs & $1.2 \times 10^{7}(100 \%)$ & $1.15 \times 10^{7}(95.83 \%)$ & $2.6 \times 10^{5}(2.17 \%)$ & $1.5 \times 10^{5}(1.25 \%)$ \\
\hline
\end{tabular}

The experiment was performed in triplciates and their mean values are shown. 


\section{A-549 Cell Line Cell Death Induced by $A$. baumannii Infection}

After infection, A-549 cell lines were incubated for $24 \mathrm{~h}$ and numbers (CFU) of $A$. baumannii were monitored for interacting or adhered bacteria on the surface of A-549 and internalized bacteria into A-549. The CFU result is presented in the Table 1. Table shows that about $41 \%$ bacteria remain un-interacted, $39.6 \%$ bacteria adhered to the surface of A-549 cells, and 18.4\% bacteria were engulfed or internalized. The CFU results of these stages are presented in the Figure 1. The infection of A-549 cell line with the A. baumannii leads to the lysis of the A-549 cell lines and also changes the morphology of A-549 cell lines that can be seen in Figure 2 .

\section{In Vitro Susceptibility of Carbapenem- Resistant $A$. baumannii against PVP- Capped AgNPs}

Synthesized PVP-capped AgNPs have maximum absorbance peak around $400 \mathrm{~nm}$ for AgNPs (Figure 3A) and size of $133 \mathrm{~nm}$ with polydispersity index of 23\% (Figure 3B). Similarly, zeta-potential of nanoparticle was found to be $-34 \mathrm{mV}$. Growth kinetics of

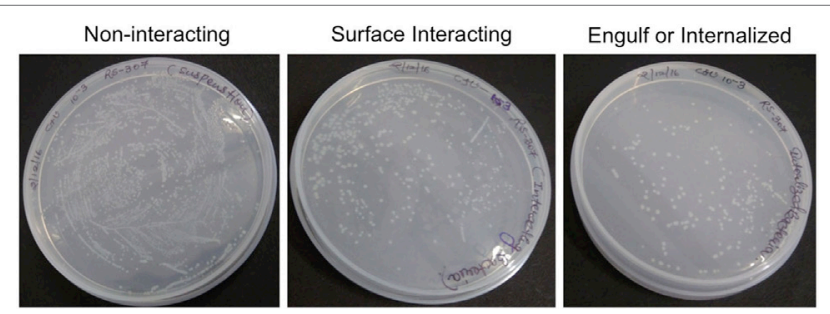

FIGURE 1 | Counting of colony-forming unit of non-interacting, surface interacting, and engulf or internalized bacteria cultured on Luria-Bertani Agar at $10^{-3}$ dilution. The triplicate experiments were performed and result of one experiment is shown.
RS-307 strain of A. baumannii was determined in the absence and presence $(30 \mu \mathrm{M})$ of PVP-capped AgNPs. Optical density was measured at $605 \mathrm{~nm}$ at an interval of $30 \mathrm{~min}$ using UV-Vis spectrophotometer. Growth curves were prepared using absorption data. The experiment was performed in triplets for untreated and treated samples and average value was used to prepare the plot. Relative growth curves were prepared for comparison purpose. The result showed that PVP-capped AgNPs showed good antimicrobial activity against carbapenem-resistant strain of A. baumannii (Figure 3C).

\section{Cytotoxicity Test of PVP-Capped AgNPs on A-549 Confirm Its Non-Toxic Nature at Its Inhibitory Concentration}

The cytotoxic effect of PVP-capped AgNPs on the human pulmonary epithelial cell lines (A-549) was identified using MTT Assay and LDH assay. Figure 4 showed that the concentration at which it showed bactericidal activity has no cytotoxicity. The $\mathrm{IC}_{50}$ value for PVP-AgNPs against A-549 cell line was found to be $130 \mu \mathrm{M}$, which is four times higher than the concentration showing antimicrobial activity. The $30 \mu \mathrm{M}$ PVP-AgNPs also does not have hemolytic activity.

\section{PVP-Capped AgNPs Prevent A-549 Cell Line Cell Death Induced by}

\section{A. baumannii}

The infected cell line of A-549 was treated with PVP-AgNPs. The infection leads to the death of A-549 cell line (Figure 5B) but PVP-AgNPs protects pulmonary cell line (A-549) from the infection of $A$. baumannii (Figure 5C). The morphologies of PVP-capped AgNPs-treated A-549 cell line (Figure 5C) are very similar to the uninfected cell lines (Figure 5A). Therefore, it can be suggested that presence of PVP-AgNPs prevent infection of carbapenem-resistant strain of A. baumannii in A549 cell line.
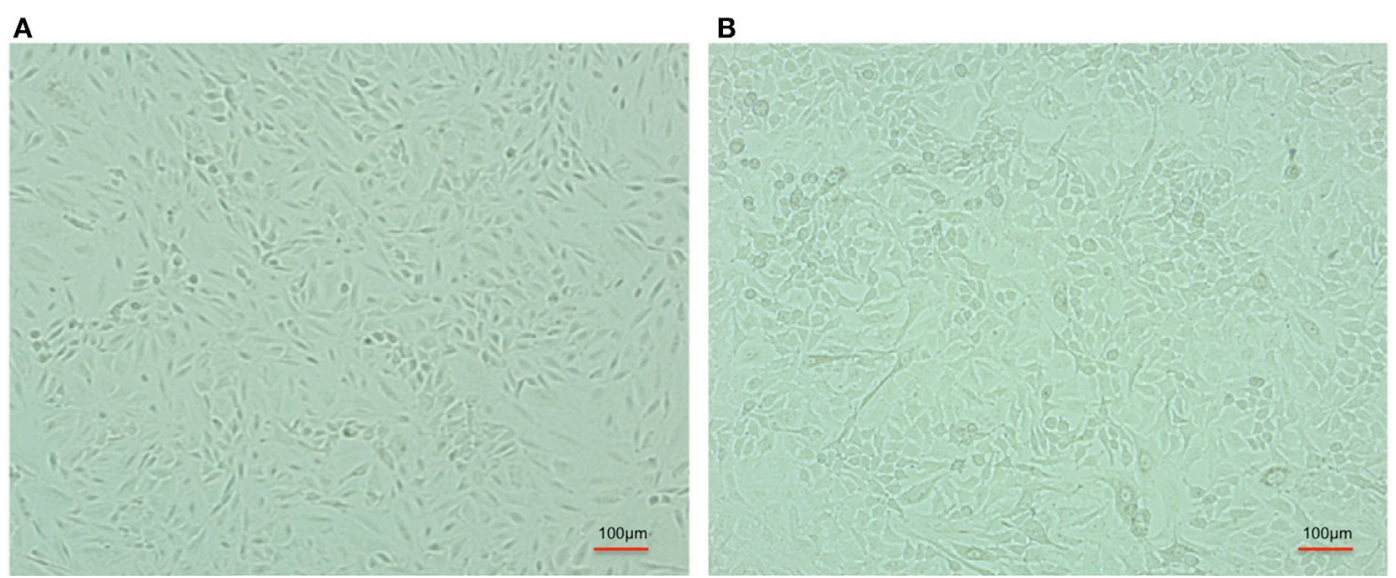

FIGURE 2 | Comparative cell line image of A-549 cell line in the absence (A) and coinfected with carbapenem-resistant strain, RS 307 of Acinetobacter baumannii (B). The experiments were performed in quadruplet. Infection leads to the lysis of A-549 cell. 

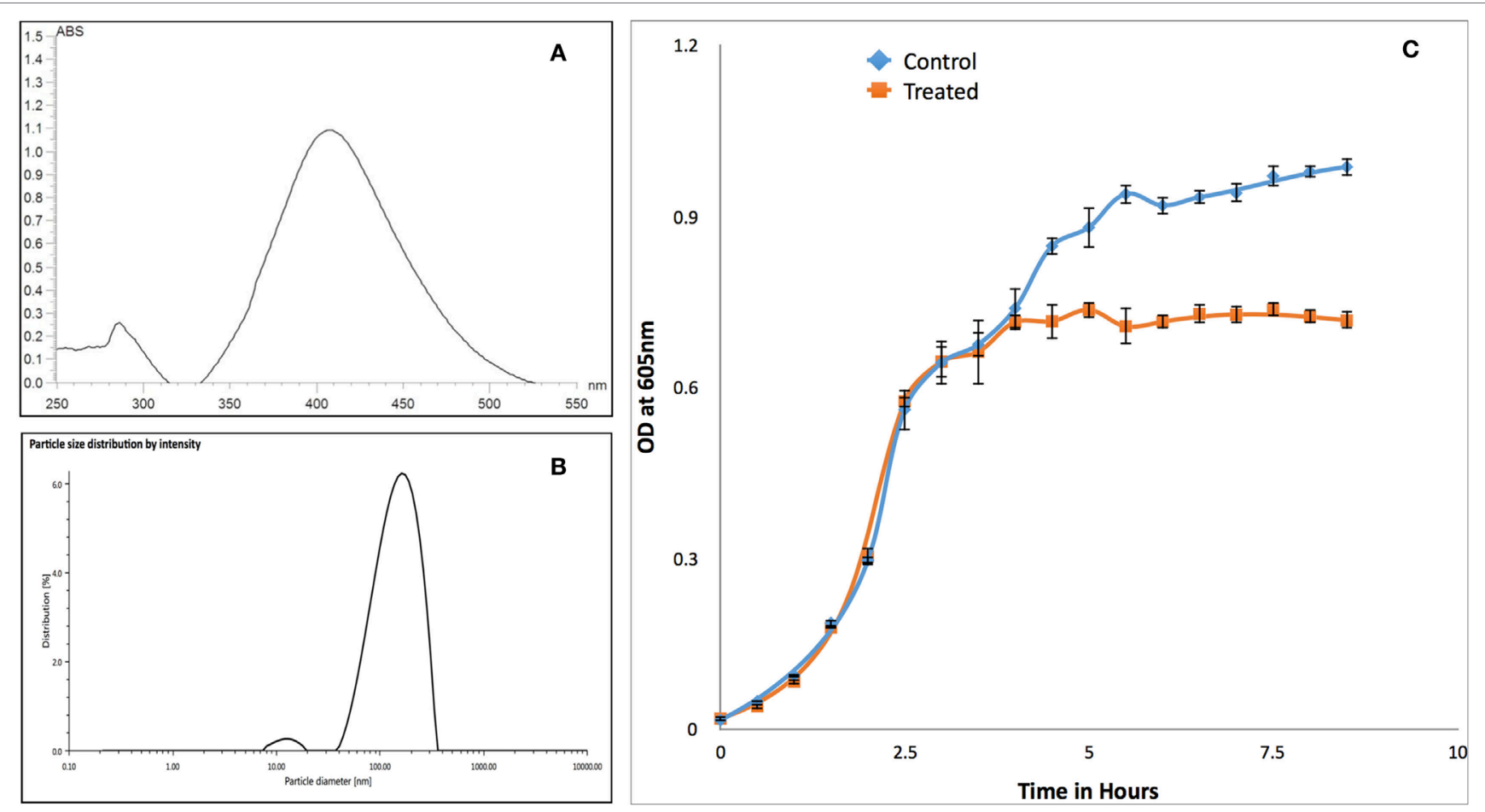

FIGURE 3 | Characterization of PVP-capped AgNPs using UV-Vis spectroscopy (A) and dynamic light scattering (B). Similarly section (C) showed comparative growth curve of RS-307 strain of Acinetobacter baumannii in the absence and presence of PVP-capped silver nanoparticles. Growth curve experiments were performed in triplicate and data are presented as mean \pm SD.
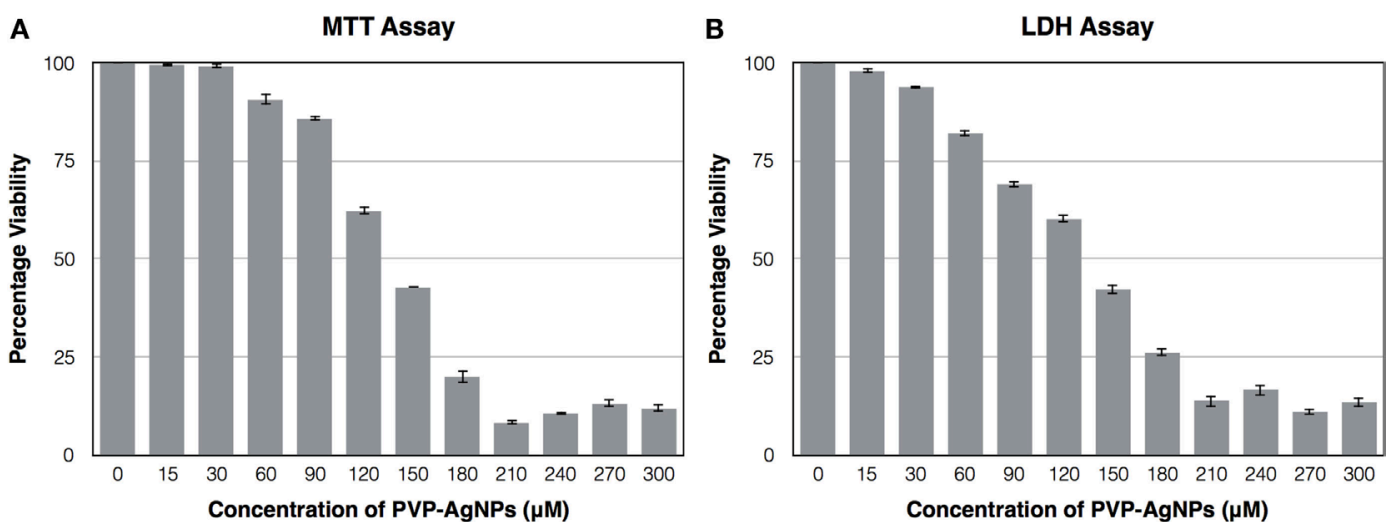

FIGURE 4 | Effect of different concentration of PVP-capped AgNPs on the viability of A-549 cell line using MTT assay (A) and LDH assay (B). The experiments were performed in triplicate and data are presented as mean \pm SD.

\section{PVP-Capped AgNPs Decreases Attachment and Internalization of A. baumannii into A-549}

Colony-forming unit counting in the absence and presence of PVP-AgNPs showed that PVP-AgNPs reduce the number of surface attached bacteria from about 40 to $2.2 \%$. The number of intracellular bacteria was also reduced from 18 to the $1.25 \%$.
Therefore, we can say that PVP-AgNPs reduces the attachment and internalization of $A$. baumannii on the pulmonary cell model.

\section{PVP-Capped AgNPs Decrease the Viability of Intracellular A. baumannii}

Intracellular viability was calculated by subtracting absorbance of infected A-549 cell line with absorbance of uninfected A-549 cell 


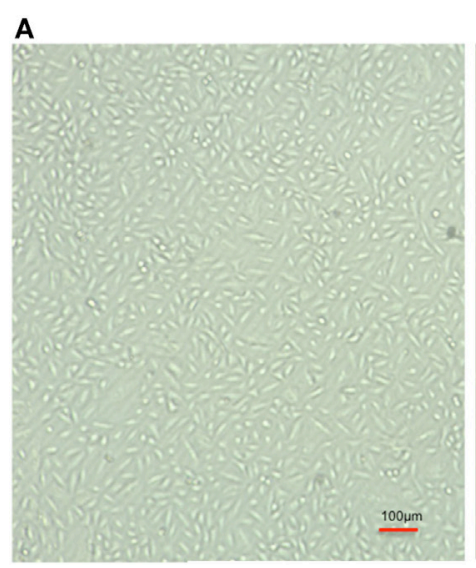

\section{B}

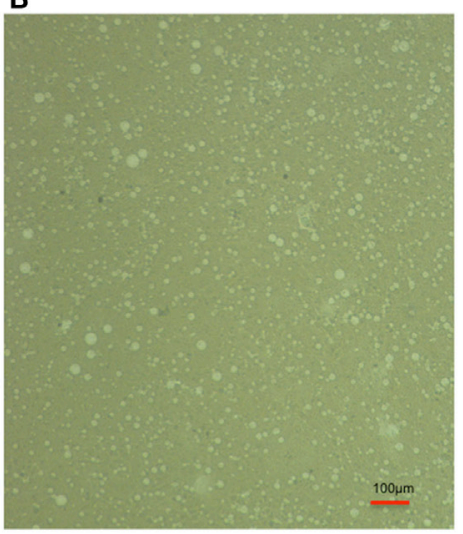

C

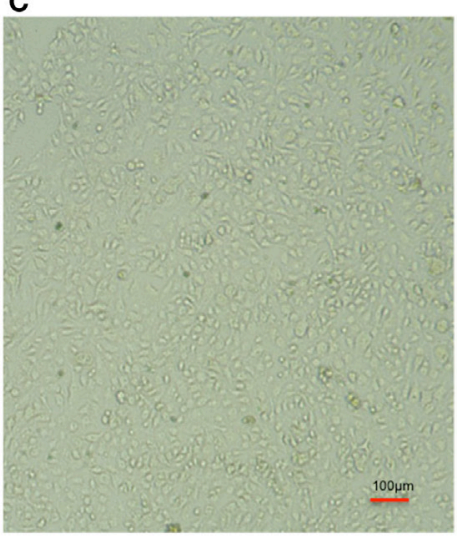

FIGURE 5 | Comparative cell line image of A-549 cell line (A), Acinetobacter baumannii infected A-549 cell line (B), and PVP-capped silver nanoparticles-treated A. baumannii infected A-549 cell line (C). Bulbs seen in panel (B) represent lysed A549 cell after A. baumannii infection. The triplicate experiments were performed and result of one experiment is shown.

lines. The result of viability test showed that there is $80 \%$ decrease in the viability of intracellular A. baumannii after treatment (OD 0.12) with $30 \mu \mathrm{M}$ PVP-AgNPs as compared to untreated sample (OD 0.56). It also enlightened that PVP-AgNPs not only inhibit free A. baumannii but also inhibit the intracellular A. baumannii.

\section{ROS Production by A549 Cell Line after \\ A. baumannii Infection}

Reactive oxygen species are used by pulmonary epithelial cells against pathogens (19). ROS can kill pathogens (such as A. baumannii) directly by causing oxidative damage to biomolecules or indirectly by stimulating pathogen elimination by various non-oxidative mechanisms (19). Therefore, we have monitored the ROS production during the infection as well as treatment. Result (Figure 6) showed that A. baumannii infection promotes threefold increase (OD at $620 \mathrm{~nm}$ is 0.83 for infected and 0.27 for uninfected) in the production of ROS. This is correlated with the previous result, which showed that ROS production increases in pulmonary epithelial cells after bacterial infection. The treatment of PVP-AgNPs shifted the ROS level to normal, which also confirms that approximately all the intracellular bacteria were killed by PVP-AgNPs. The result is correlated with the bacterial viability assay, which also confirms that about $80 \%$ intracellular bacteria were killed by the PVP-AgNPs.

\section{PVP-Capped AgNPs Treatment Changes the SDS Protein Profiling}

The estimated value of protein isolated from suspension bacteria, internalized bacteria, cell line blank, and coinfected cell line were found to be $4.20,1.51,2.0$, and $1.77 \mu \mathrm{g} / \mu \mathrm{l}$, respectively. The SDS-PAGE profiling of RS-307 bacterial proteins (Figure 7A) and A-549 cell line proteins (Figure 7B) in the presence and absence of each other. The result confirms that

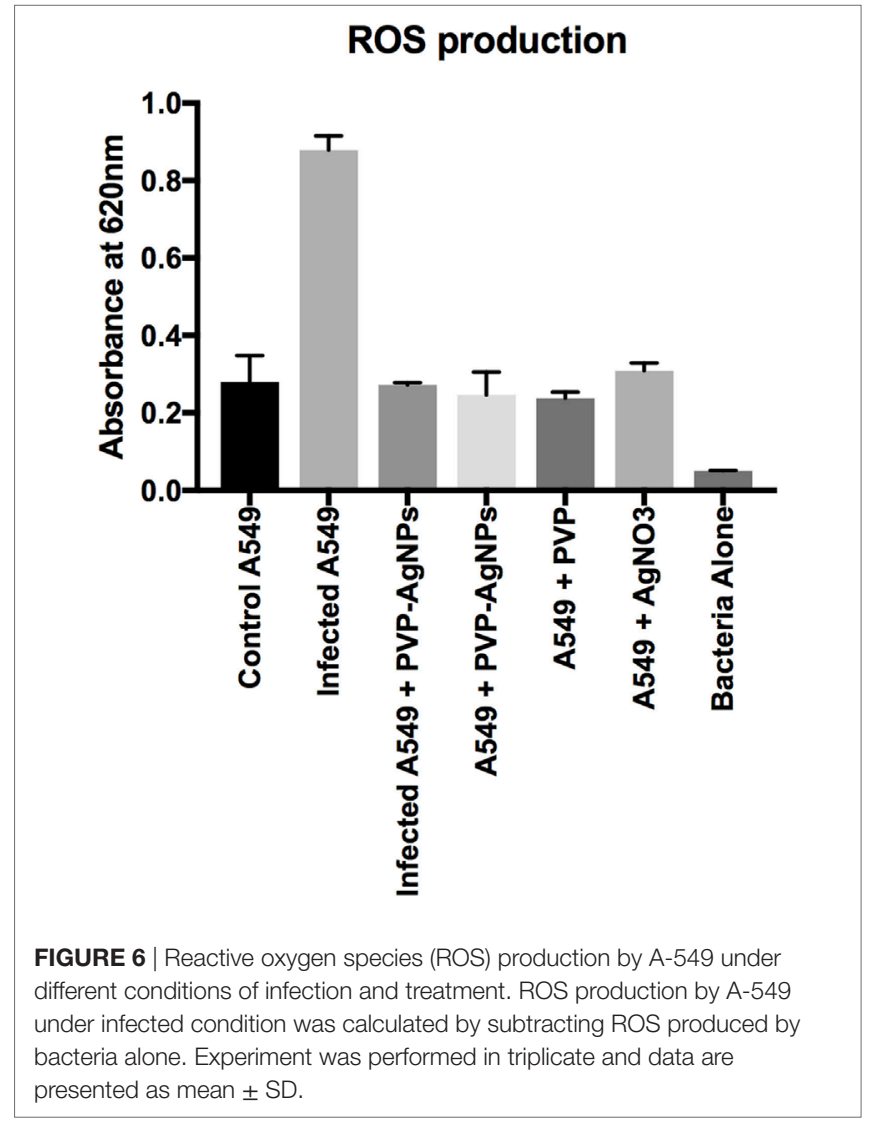

after coinfection, protein with $43 \mathrm{kDa}$ overexpressed while a protein with $35 \mathrm{kDa}$ undergoes downregulation in the protein profiling of bacteria (Figure 7A). Similarly after infection a protein about $40 \mathrm{kDa}$ expression is markedly decreased and banding pattern of A549 is totally different after Acinetobacter infection. 

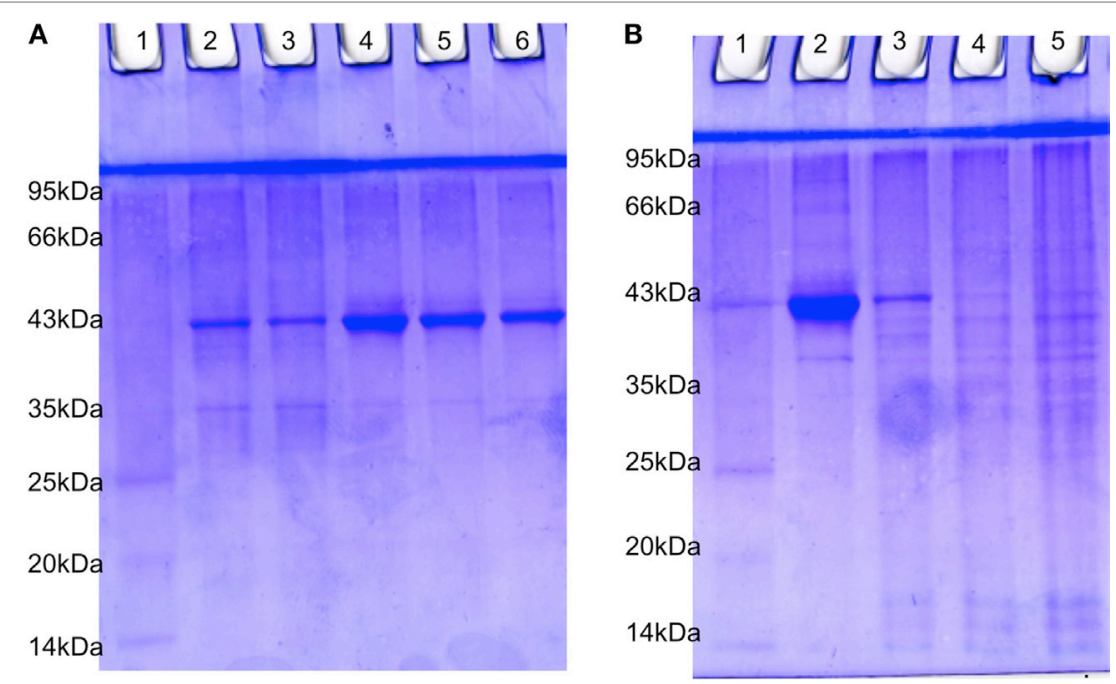

FIGURE 7 | SDS-PAGE analysis of 15 gg protein extracted from (A) RS-307 strain of Acinetobacter baumannii cultured in Dulbecco's Modified Eagle Medium (Lane 2, 3) and RS-307 cocultured and isolated from A-549 cell line, i.e., internalized bacteria (Lane 4-6). (B) A-549 cell line (Lane 2) as well as A-549 cell line infected with carbapenem-resistant strain RS-307 of A. baumannii (Lane 3-5). Lane 1 of both the gels represent protein marker.

\section{DISCUSSION}

Acinetobacter baumannii is a Gram-negative multi drug-resistant bacterium causing nosocomial infection. Emergence of drug resistance in A. baumannii will lead to the high mortality and morbidity. Therefore, it is a high time to develop an alternative drug against carbapenem-resistant strain of A. baumannii. There are different approaches including herbal-based $(5,20,21)$, nanomaterial-based $(12,22)$ and combination therapy (23-29), which have been tried recently against $A$. baumannii and few of them have shown very promising results.

Silver nanoparticles have recently emerged as antimicrobial agents for treating bacterial infections. PVP-capped AgNPs $(11,12)$ and citrate-capped AgNPs (22) were found to inhibit the growth of A. baumannii. Interaction of AgNPs with different cell models and their cellular effect have been reviewed recently (30) and showed the involvement of ROS during interaction of AgNPs with different cell lines. Recently, it is also reported that acinetin-505, a small lipopeptide-like compound, have role in the interaction of A. baumannii with pulmonary cells model (31). Most of the studied done so far have highlighted the use of AgNPs against A. baumannii in suspension form but less have been studied about the inhibitory role of AgNPs in the infection of A. baumannii to the human cell model.

Therefore, we have chemically synthesized PVP-capped AgNPs and characterized them for size and zeta-potential. The results confirm the formation of PVP-capped AgNPs with size around $100 \mathrm{~nm}$. Synthesized nanoparticles were found active against carabpenem-resistant strain of $A$. baumannii, hence further used for its effect during infection of $A$. baumannii to human pulmonary cells model. Result of coinfection showed that A. baumannii leads to the death of basal epithelial cell line, i.e., A-549 and infection of A. baumannii to human pulmonary cells was inhibited by PVP-AgNPs. Similarly, PVP-AgNPs have no or very less cytotoxic effect at the bacterial inhibitory concentration. Likewise, it was also seen that there is a decrease of $80 \%$ viability of the intracellular bacteria. Therefore, present study suggest that PVP-AgNPs can be developed as a good alternative to carbapenem (beta-lactam), which inhibit the growth of carbapenem-resistant strain of A. baumannii.

\section{CONCLUSION}

Acinetobacter baumannii causes pneumonia via targeting human pulmonary cells. Hence, human alveolar basal epithelial cell line A-549 was selected as a model to study the infection caused by A. baumannii. The present study concludes that during infection of $A$. baumannii about $40 \%$ bacteria adhere to the surface of A549 while about $20 \%$ get internalized inside the pulmonary cell line. We have also seen that during Acinetobacter infection, ROS concentration was found to increase by threefold. We have synthesized PVP-capped AgNPs using chemical methods and tested its efficacy against carbapenem-resistant strain of A. baumannii. The result showed that $30 \mu \mathrm{M}$ PVP-AgNPs inhibit growth of $A$. baumannii in in vitro experiments. We have also shown that this concentration of PVP-AgNPs does not show any cytotoxic effect on the human pulmonary cell line with $\mathrm{IC}_{50}$ value of $130 \mu \mathrm{M}$. The PVP-AgNPs treatment causes about $80 \%$ decrease in the viability of the intracellular bacteria. Therefore, based on the result of the present study it can be concluded that PVP-capped silver nanoparticle can be a suitable replacement to the current antibiotics used against A. baumannii. Pulmonary cell targeted delivery of PVP-AgNPs in animal model can be further studied to use this molecule as a suitable drug against A. baumannii. 


\section{AUTHOR CONTRIBUTIONS}

Conceived and designed the experiments, analyzed the data, wrote the manuscript: VT, Performed the experiments: VT, MT, and VS. Proofread of final version: VT, and MT.

\section{REFERENCES}

1. Gupta E, Mohanty S, Sood S, Dhawan B, Das BK, Kapil A. Emerging resistance to carbapenems in a tertiary care hospital in north India. Indian J Med Res (2006) 124(1):95-8.

2. Tiwari V, Kapil A, Moganty RR. Carbapenem-hydrolyzing oxacillinase in high resistant strains of Acinetobacter baumannii isolated from India. Microb Pathog (2012) 53(2):81-6. doi:10.1016/j.micpath.2012. 05.004

3. Tiwari V, Vashistt J, Kapil A, Moganty RR. Comparative proteomics of inner membrane fraction from carbapenem-resistant Acinetobacter baumannii with a reference strain. PLoS One (2012) 7(6):e39451. doi:10.1371/journal. pone.0039451

4. Tiwari V, Moganty RR. Conformational stability of OXA-51 beta-lactamase explains its role in carbapenem resistance of Acinetobacter baumannii. J Biomol Struct Dyn (2014) 32(9):1406-20. doi:10.1080/07391102.2013. 819789

5. Roy R, Tiwari M, Donelli G, Tiwari V. Strategies for combating bacterial biofilms: a focus on anti-biofilm agents and their mechanisms of action. Virulence (2017). doi:10.1080/21505594.2017.1313372

6. Verma P, Tiwari M, Tiwari V. In-silico high throughput virtual screening and molecular dynamics simulation study to identify inhibitor for AdeABC efflux pump of Acinetobacter baumannii. J Biomol Struct Dyn (2017). doi:10.1080/ 07391102.2017.1317025

7. Smani Y, Docobo-Perez F, McConnell MJ, Pachon J. Acinetobacter baumannii-induced lung cell death: role of inflammation, oxidative stress and cytosolic calcium. Microb Pathog (2011) 50(5):224-32. doi:10.1016/j. micpath.2011.01.008

8. Lee JC, Oh JY, Kim KS, Jeong YW, Park JC, Cho JW. Apoptotic cell death induced by Acinetobacter baumannii in epithelial cells through caspase-3 activation. APMIS (2001) 109(10):679-84. doi:10.1034/j.1600-0463.2001. d01-132.x

9. Lee JC, Koerten H, van den Broek P, Beekhuizen H, Wolterbeek R, van den Barselaar M, et al. Adherence of Acinetobacter baumannii strains to human bronchial epithelial cells. Res Microbiol (2006) 157(4):360-6. doi:10.1016/j. resmic.2005.09.011

10. Choi CH, Lee JS, Lee YC, Park TI, Lee JC. Acinetobacter baumannii invades epithelial cells and outer membrane protein A mediates interactions with epithelial cells. BMC Microbiol (2008) 8:216. doi:10.1186/1471-2180$8-216$

11. Tiwari V, Khokar MK, Tiwari M, Barala S, Kumar M. Anti-bacterial activity of polyvinyl pyrrolidone capped silver nanoparticles on the carbapenem resistant strain of Acinetobacter baumannii. J Nanomed Nanotechnol (2014) 5(6):246. doi:10.4172/2157-7439.1000246

12. Tiwari M, Raghav R, Tiwari V. Comparative anti-bacterial activity of differently capped silver nanomaterial on the carbapenem sensitive and resistant strains of Acinetobacter baumannii. J Nanomed Nanotechnol (2015) 6:314. doi:10.4172/2157-7439.1000314

13. Hitchman A, Smith GH, Ju-Nam Y, Sterling M, Lead JR. The effect of environmentally relevant conditions on PVP stabilised gold nanoparticles. Chemosphere (2013) 90(2):410-6. doi:10.1016/j.chemosphere.2012. 07.041

14. Kora AJ, Rastogi L. Enhancement of antibacterial activity of capped silver nanoparticles in combination with antibiotics, on model Gram-negative and Gram-positive bacteria. Bioinorg Chem Appl (2013) 2013:871097. doi:10.1155/2013/871097

15. Zhang H, Zhang C. Transport of silver nanoparticles capped with different stabilizers in water saturated porous media. J Mater Environ Sci (2014) 5(1): 231-6.

\section{ACKNOWLEDGMENTS}

VT would like to thank SERB, DST, India for Start Up grant (SB/YS/ LS-07/2014). VS wants to thank UGC for JRF-fellowship. MT wants to thank Central University of Rajasthan for her Ph.D. fellowship.

16. Setyawati MI, Yuan X, Xie J, Leong DT. The influence of lysosomal stability of silver nanomaterials on their toxicity to human cells. Biomaterials (2014) 35(25):6707-15. doi:10.1016/j.biomaterials.2014.05.007

17. Gnanadhas DP, Ben Thomas M, Thomas R, Raichur AM, Chakravortty D. Interaction of silver nanoparticles with serum proteins affects their antimicrobial activity in vivo. Antimicrob Agents Chemother (2013) 57(10):4945-55. doi:10.1128/AAC.00152-13

18. Tiwari M, Roy R, Tiwari V. Screening of herbal-based bioactive extract against carbapenem-resistant strain of Acinetobacter baumannii. Microb Drug Resist (2016) 22(5):364-71. doi:10.1089/mdr.2015.0270

19. Paiva CN, Bozza MT. Are reactive oxygen species always detrimental to pathogens? Antioxid Redox Signal (2014) 20(6):1000-37. doi:10.1089/ars. 2013.5447

20. Tiwari V, Roy R, Tiwari M. Antimicrobial active herbal compounds against Acinetobacter baumannii and other pathogens. Front Microbiol (2015) 6:618. doi:10.3389/fmicb.2015.00618

21. Tiwari V, Tiwari D, Patel V, Tiwari M. Effect of secondary metabolite of Actinidia deliciosa on the biofilm and extra-cellular matrix components of Acinetobacter baumannii. Microb Pathog (2017) 110:345-51. doi:10.1016/j. micpath.2017.07.013

22. Wan G, Ruan L, Yin Y, Yang T, Ge M, Cheng X. Effects of silver nanoparticles in combination with antibiotics on the resistant bacteria Acinetobacter baumannii. Int J Nanomedicine (2016) 11:3789-800. doi:10.2147/IJN. S104166

23. Saballs M, Pujol M, Tubau F, Pena C, Montero A, Dominguez MA, et al. Rifampicin/imipenem combination in the treatment of carbapenem-resistant Acinetobacter baumannii infections. J Antimicrob Chemother (2006) 58(3):697-700. doi:10.1093/jac/dkl274

24. Song JY, Lee J, Heo JY, Noh JY, Kim WJ, Cheong HJ, et al. Colistin and rifampicin combination in the treatment of ventilator-associated pneumonia caused by carbapenem-resistant Acinetobacter baumannii. Int J Antimicrob Agents (2008) 32(3):281-4. doi:10.1016/j.ijantimicag.2008.04.013

25. Jain J, Arora S, Rajwade JM, Omray P, Khandelwal S, Paknikar KM. Silver nanoparticles in therapeutics: development of an antimicrobial gel formulation for topical use. Mol Pharm (2009) 6(5):1388-401. doi:10.1021/ mp900056g

26. Aydemir H, Akduman D, Piskin N, Comert F, Horuz E, Terzi A, et al. Colistin vs. the combination of colistin and rifampicin for the treatment of carbapenem-resistant Acinetobacter baumannii ventilator-associated pneumonia. Epidemiol Infect (2013) 141(6):1214-22. doi:10.1017/S095026881200194X

27. Garnacho-Montero J, Amaya-Villar R, Gutierrez-Pizarraya A, EspejoGutierrez de Tena E, Artero-Gonzalez ML, Corcia-Palomo Y, et al. Clinical efficacy and safety of the combination of colistin plus vancomycin for the treatment of severe infections caused by carbapenem-resistant Acinetobacter baumannii. Chemotherapy (2013) 59(3):225-31. doi:10.1159/000356004

28. Hiraki Y, Yoshida M, Masuda Y, Inoue D, Tsuji Y, Kamimura H, et al. Successful treatment of skin and soft tissue infection due to carbapenem-resistant Acinetobacter baumannii by ampicillin-sulbactam and meropenem combination therapy. Int J Infect Dis (2013) 17(12):e1234-6. doi:10.1016/j. ijid.2013.05.002

29. Habash MB, Park AJ, Vis EC, Harris RJ, Khursigara CM. Synergy of silver nanoparticles and aztreonam against Pseudomonas aeruginosa PAO1 biofilms. Antimicrob Agents Chemother (2014) 58(10):5818-30. doi:10.1128/ AAC.03170-14

30. Zhang XF, Shen W, Gurunathan S. Silver nanoparticle-mediated cellular responses in various cell lines: an in vitro model. Int J Mol Sci (2016) 17(10):1603. doi:10.3390/ijms17101603

31. Rumbo-Feal S, Perez A, Ramelot TA, Alvarez-Fraga L, Vallejo JA, Beceiro A, et al. Contribution of the A. baumannii A1S_0114 gene to the interaction 
with eukaryotic cells and virulence. Front Cell Infect Microbiol (2017) 7:108. doi:10.3389/fcimb.2017.00108

Conflict of Interest Statement: The authors declare that the research was conducted in the absence of any commercial or financial relationships that could be construed as a potential conflict of interest.
Copyright $\odot 2017$ Tiwari, Tiwari and Solanki. This is an open-access article distributed under the terms of the Creative Commons Attribution License (CC BY). The use, distribution or reproduction in other forums is permitted, provided the original author(s) or licensor are credited and that the original publication in this journal is cited, in accordance with accepted academic practice. No use, distribution or reproduction is permitted which does not comply with these terms. 